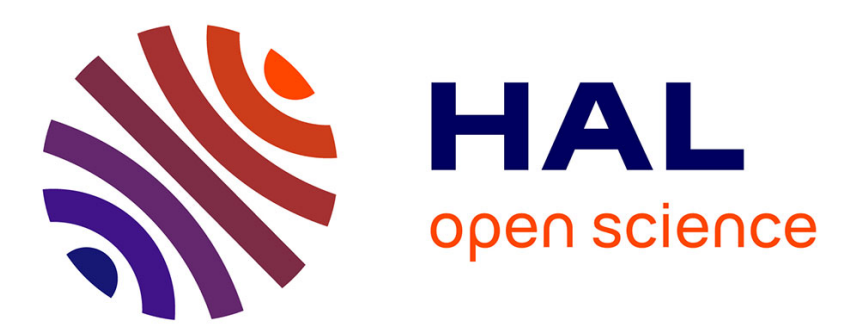

\title{
Evaluation of Two Commercial Kits on the Automated ELITe InGenius PCR Platform for Molecular Diagnosis of Toxoplasmosis
}

Céline Nourrisson, Maxime Moniot, Philippe Poirier, Yvon Sterkers

\section{To cite this version:}

Céline Nourrisson, Maxime Moniot, Philippe Poirier, Yvon Sterkers. Evaluation of Two Commercial Kits on the Automated ELITe InGenius PCR Platform for Molecular Diagnosis of Toxoplasmosis. Journal of Molecular Diagnostics, 2021, 23 (7), pp.865-871. 10.1016/j.jmoldx.2021.04.004 . hal03323951

\section{HAL Id: hal-03323951 \\ https://hal.science/hal-03323951}

Submitted on 23 Aug 2021

HAL is a multi-disciplinary open access archive for the deposit and dissemination of scientific research documents, whether they are published or not. The documents may come from teaching and research institutions in France or abroad, or from public or private research centers.
L'archive ouverte pluridisciplinaire HAL, est destinée au dépôt et à la diffusion de documents scientifiques de niveau recherche, publiés ou non, émanant des établissements d'enseignement et de recherche français ou étrangers, des laboratoires publics ou privés. 


\title{
Evaluation of two commercial kits on the automated ELITe InGenius ${ }^{\text {TM }}$ PCR platform for molecular diagnosis of toxoplasmosis Céline Nourrisson ${ }^{1,2, *, \#}$, Maxime Moniot ${ }^{1}$, Philippe Poirier ${ }^{1,2}$, Yvon Sterkers $^{3}$
}

${ }^{1}$ Laboratoire de Parasitologie-Mycologie, CHU Clermont-Ferrand, 3IHP, France

${ }^{2}$ Université Clermont Auvergne, CNRS UMR 6023, Laboratoire Microorganismes : Génome et Environnement, Clermont-Ferrand, France

3 Univ. Montpellier, CNRS, IRD, CHU Montpellier, "MiVEGEC", Department of Parasitology-Mycology \& Molecular Biology Pole of the National Reference Center for Toxoplasmosis, , Montpellier, France

*Corresponding author : Dr. Céline Nourrisson

e-mail address: $\underline{c}$ _nourrisson@chu-clermontferrand.fr

\#Address correspondence to Céline Nourrisson:

Service de Parasitologie-Mycologie, Centre de Biologie - CHU Gabriel Montpied

58 rue Montalembert 63000 Clermont-Ferrand, FRANCE

Phone number: +334.73.75.01.95 / Fax number: +334.73.75.01.96

This manuscript has been published, please cite: Evaluation of two commercial kits on the automated ELITe InGenius PCR platform for molecular diagnosis of toxoplasmosis. Nourrisson C, Moniot M, Poirier P, Sterkers Y. J Mol Diagn. 2021 May 4:S1525-1578(21)00113-6. doi: 10.1016/j.jmoldx.2021.04.004. PMID: 33962054

\begin{abstract}
Molecular diagnosis of toxoplasmosis is essential for establishing the diagnosis of congenital contaminations and for primary infection or reactivation of immunocompromised patients. An integrated extraction and real-time PCR-based system is of particular interest in this context. Commercial kits for automated extraction and amplification steps are now available. Here we assessed two commercial PCR assays for this diagnosis, those of Bio-Evolution and Elitech, on the ELITe InGenius ${ }^{\mathrm{TM}}$ platform (ELITechGroup). The Bio-Evolution assay showed a specificity and a sensitivity of $100 \%$ on clinical samples, but a lower analytical detection threshold than the Elitech assay. The latter showed a specificity of $100 \%$ and a sensitivity of 96\%. The SP1000 cartridges (Elitech), which allow DNA extraction from $1 \mathrm{~mL}$ of template, showed very interesting performances on amniotic fluids samples. Overall, the two kits had very good performances on the InGenius ${ }^{\mathrm{TM}}$ platform, which offers a turn-key solution suitable for the molecular diagnosis of toxoplasmosis.
\end{abstract}

\section{Introduction}

Toxoplasmosis is a zoonotic disease caused by the protozoan Toxoplasma gondii belonging to the phylum of Apicomplexa. It is an obligate intracellular parasite with a worldwide distribution, infecting mammals and birds. Nowadays, direct search of $T$. gondii for the diagnosis of congenital toxoplasmosis as well as acute disease in immunocompromised patients is based on molecular tools.
Although "in-house" quantitative PCR (qPCR) techniques are still widely used for these diagnoses (1), there is a growing interest of medical laboratories for commercial kits due to their ease and speed of use, their standardization fitting with the quality management system policy and their performances $(2,3)$. DNA extraction is also a critical step in diagnoses as sensitive as toxoplasmosis. Automated DNA extraction methods were shown to be more reproducible than non-automated ones and perform well (4). Hence, a 
combination of automated DNA extraction with qPCR not only takes advantages of both tools, but also reduces technical time, reporting delays and risk of errors. The ELITe InGenius ${ }^{\mathrm{TM}}$ platform (ELITechGroup, Inc., Bothell, WA, USA) is an open fully automated sample-to-result PCR system, allowing nucleic acid extraction and real-time PCR amplification of up to twelve samples. In this study, the performances of two commercial PCR assays, the Bio-Evolution Toxoplasma gondii detection kit (Bio-Evolution, BussySaint-Martin, France) and the Toxoplasma ELITe MGB assay (ELITechGroup), were evaluated when performed on the ELITe InGenius $^{\mathrm{TM}}$ platform.

\section{Materials and methods \\ Samples.}

A freeze-dried calibrated suspension $\left(10^{4}\right.$ Toxoplasma/mL, T. gondii type II) was kindly provided by the Molecular Biology 'Pole' of the French National Reference Center for Toxoplasmosis (NRC-T) (http://cnrtoxoplasmose.chu-

reims.fr/?lang=en, last access on 03/17/2021) (5). A panel of 15 QCMD (Quality Control for Molecular Diagnostics, Glasgow, Scotland, UK) quality controls was included in this study. It consisted of eight vials of lyophilized amniotic fluid samples and seven vials of lyophilized plasma samples spiked or not with various concentrations of $T$. gondii (TGDNA18 and TGDNA20 panels). All these freeze-dried samples were reconstituted by adding $2.0 \mathrm{~mL}$ of sterile molecular-grade water as recommended. For the TGDNA18 panel, suspensions were centrifuged after $5 \mathrm{~min}$, then $1.8 \mathrm{~mL}$ of supernatant were discarded and DNA from the pellet $(200 \mu \mathrm{L})$ was extracted (see below). For the TGDNA20 panel, which consisted of amniotic fluids only, three comparable vials of each three controls were tested with two extraction protocols: after $5 \mathrm{~min}$, DNA from $1 \mathrm{~mL}$ or $200 \mu \mathrm{L}$ of homogeneized suspension was extracted (see below). Thirty-one clinical samples stored at $-20^{\circ} \mathrm{C}$ following routine molecular diagnosis between 2018 and 2019 were also kindly provided by the French NRC-T. It included positive, weakly positive or negative (blind selection) peripheral bloods $(\mathrm{n}=18)$, cord bloods $(n=3)$, placentas $(n=6)$ and amniotic fluids $(n=4)$. Before enrolment of a sample, diagnosis of toxoplasmosis was either excluded or asserted by molecular, serological and/or clinical follow-up of patients. All samples were tested in blind. For congenital toxoplasmosis, diagnosis of mothers and offsprings were classified as defined by the European Research Network on Congenital Toxoplasmosis group (6). Comparative immunoblot (IgG and $\operatorname{IgM})$ at birth was performed to support diagnosis (7). Positive samples in immunocompromised were graded according to the European Group for Blood and Marrow Transplantation Infectious Diseases Working Party classification as "Toxoplasma infection" and "Toxoplasma disease" (8).

DNA extraction. Regarding pre-analytical steps on clinical samples, amniotic fluids $(4 \mathrm{~mL})$ were centrifuged (10 $\mathrm{min}$ at 16,000 g). Placentas $(300 \mathrm{~g})$ were ground and trypsinized with $0.6 \mathrm{~g}$ Trypsin at $37^{\circ} \mathrm{C}$ during 2 hours under constant magnetic stirring, then filtered. The pellet obtained by centrifugation $1,750 \mathrm{x} \mathrm{g}, 10 \mathrm{~min}$ was washed twice by PBS1X, and lysed with proteinase $\mathrm{K}$ (Euromedex, France). Buffy coat portions $(300 \mu \mathrm{L})$ isolated from whole blood $(4 \mathrm{~mL})$ after centrifugation for 10 $\min$ at $1,750 \times \mathrm{g}$, were also lysed with proteinase K (Euromedex, France). Then, DNA extractions were carried on the ELITe InGenius ${ }^{\mathrm{TM}}$ platform (ELITechGroup). All samples were first processed using the extraction cartridges ELITe InGenius ${ }^{\mathrm{TM}} \quad$ SP 200 (ELITechGroup) following the manufacturer's instructions, processing $200 \mu \mathrm{L}$ of pre-treated sample and eluting nucleic acids in a $100 \mu \mathrm{L}$ final volume. Four clinical samples of amniotic fluids 
and the three control samples of amniotic fluids of the TGDNA20 panel, each in three different vials, were also extracted with the extraction cartridges ELITe InGenius $^{\mathrm{TM}}$ SP 1000 (ELITechGroup) (nucleic acids from $1000 \mu \mathrm{L}$ of pre-treated sample eluted in $100 \mu \mathrm{L}$ ). Manufacturer's internal control (CPE - Internal Control, ELITechGroup), compatible with the Toxoplasma ELITe MGB assay (ELITechGroup), was added during the extraction process.

PCR assays. Two commercial kits were evaluated, the Toxoplasma ELITe MGB assay (ELITechGroup) and the BioEvolution Toxoplasma gondii detection kit (Bio-Evolution) (Table 1). All DNA amplifications were performed on the ELITe InGenius ${ }^{\mathrm{TM}}$ apparatus (ELITechGroup), following the DNA extraction step on the same apparatus. The set parameters for DNA amplification complied with the protocols defined by each manufacturer. Clinical and control samples were tested in duplicate, and repeated in triplicate on the same intial DNA extract when discrepant qualitative results between both qPCR assays were observed. In all analyses the same detection threshold was used.

PCR perfomances. Limit of detection, range and linearity were approached using logarithmic serial dilutions of the DNA extract of the calibrated Toxoplasma suspension. The six concentrations tested ranged from $10^{4}$ to $10^{-1} T$. gondii $/ \mathrm{mL}$. All concentrations were tested in triplicate. A performance score was determined based on the number of positive samples divided by the total number of PCR wells (9).

Statistical analysis. Crossing threshold $(\mathrm{Ct})$ values were used to elaborate the standard curve and to determine the efficiency of each PCR method. Delta Ct is the difference between $\mathrm{Ct}$ values obtained with each assay for a same sample. Means, standard deviations, coefficients of variation $(\mathrm{CV})$ and correlations $\left(\mathrm{R}^{2}\right)$ were calculated using Microsoft ${ }^{\circledR}$ Excel $^{\circledR}$ software (version 15.0.5031.1000). Slopes of standard curves allowed determination of PCR efficiency in conformity with the formula $10^{(-1 / \text { slope })}-1$. Slopes between -3.1 and -3.6 giving reaction efficiencies between 90 and $110 \%$ are typically acceptable (Applied Biosystems application note "Amplification efficiency of TaqMan gene expression assays", Thermo Fisher Scientific Inc., Waltham, MA, USA). Slopes were calculated when all triplicates were positive and $\mathrm{SD}<0.5$. Data obtained by both assays were compared using chi-square statistic with Yates correction when applicable. Agreement between both assays for the $\mathrm{Ct}$ values of positive clinical samples was evaluated by a Bland-Altman plot, which is a graphical representation of the difference of $\mathrm{Ct}$ in abscissa plotted against the mean of $\mathrm{Ct}$ values in ordinate, for each samples analysed by both assays (10).

\section{Ethical approval and informed consent.}

This study corresponds to a noninterventional retrospective study and followed the relevant guidelines and regulations according to the French Health Public Law (CSP Art L1121-1.1). In particular, it does not include potentially identifying

patient/participant informations. Informed consent was obtained for sampling and analyzing amniotic fluids; the rest of the study is exempted from informed consent requirement and does not require approval by an ethics committee.

\section{Results}

PCR performance score and efficiency
using Toxoplasma calibrated suspensions. Serial dilutions of a calibrated Toxoplasma suspension were performed from $10^{4}$ to $10^{-1}$ parasites $/ \mathrm{mL}$. Qualitative and quantative results are reported in Table 2. The lowest parasite concentrations, i.e. 1 and $0.1 \mathrm{~T} / \mathrm{mL}$. were inconstantly amplified (Table S1). The PCR performance score were 15/18 $(83.3 \%)$ with Bio-Evolution assay, and reached $17 / 18(94.4 \%)$ with Elitech. 


\begin{tabular}{lcc}
\hline & $\begin{array}{c}\text { Toxoplasma gondii detection } \\
\text { kit (Bio-Evolution) }\end{array}$ & $\begin{array}{c}\text { Toxoplasma ELITe MGB } \\
\text { assay (Elitech) }\end{array}$ \\
\hline DNA target & rep529 & rep529 \\
Type of probe & TaqMan (FAM-BHQ1) & TaqMan (FAM-MGB) \\
Internal control & $\begin{array}{c}\text { Not specified (for DNA } \\
\text { amplification only) }\end{array}$ & $\begin{array}{c}\text { Artificial DNA sequence (for } \\
\text { DNA extraction and } \\
\text { amplification) }\end{array}$ \\
DNA input volume $(\mu \mathrm{L})$ & 5 & 10 \\
PCR mix volume $(\mu \mathrm{L})$ & 20 & 20 \\
No. of cycles & 40 & 45 \\
Uracil-DNA glycosylase & No & Yes \\
\hline
\end{tabular}

Table 1. Main technical characteristics of the two PCR assays.

\begin{tabular}{ccccc}
\hline \multirow{2}{*}{$\begin{array}{c}\text { Concentration }(T . \\
\begin{array}{c}\text { gondii } \\
\text { parasites/mL) }\end{array}\end{array}$} & $\begin{array}{c}\text { Qualitative results } \\
\text { (No. of positive reactions/no. of } \\
\text { reactions performed) }\end{array}$ & \multicolumn{2}{c}{$\begin{array}{c}\text { Quantitative results } \\
\text { (mean Ct values } \pm \text { SD*) }\end{array}$} \\
\cline { 2 - 5 } Bio-Evolution & Elitech & Bio-Evolution & Elitech \\
\hline 10,000 & $3 / 3$ & $3 / 3$ & $19.2 \pm 0.1$ & $21.3 \pm 0.1$ \\
1,000 & $3 / 3$ & $3 / 3$ & $23.4 \pm 0.1$ & $25.9 \pm 0.2$ \\
100 & $3 / 3$ & $3 / 3$ & $27.0 \pm 0.3$ & $29.3 \pm 0.3$ \\
10 & $3 / 3$ & $3 / 3$ & $29.5 \pm 0.4$ & $32.1 \pm 0.2$ \\
1 & $2 / 3$ & $3 / 3$ & $34.6 \pm 2.6$ & $36.1 \pm 1.0$ \\
0.1 & $1 / 3$ & $2 / 3$ & 33.4 & $37.6 \pm 2.2$ \\
\hline PCR performance & $15 / 18(83.3 \%)$ & $17 / 18$ & $/$ & $90.3 \%$ \\
score & $/ 94.4 \%)$ & & $94.9 \%$ & $/$ \\
\hline $\begin{array}{c}\text { Efficiency }(-1+ \\
\left.10^{(-1 / \text { slope) }}\right)\end{array}$ & $/$ & $/$ & & \\
\hline
\end{tabular}

Table 2. Performance of the two PCR assays using DNA serial dilutions of a calibrated Toxoplasma suspension.

*SD: standard deviation. SDs were calculated on the basis of the positive values only. 
The chi-square statistic with Yates correction is 0.281 . The $p$-value is 0.596 ; the difference was not found significant at $p<0.050$. The PCR efficiencies were $94.9 \%$ and $90.3 \%$ for Bio-Evolution and Elitech, respectively. Linearity and range were evaluated by constructing a calibration curve when all triplicates were positive with $\mathrm{SD}<0.5$. Linearity $\left(\mathrm{R}^{2}>0.987\right)$ and range extended from 10 to $10^{4}$ parasites $/ \mathrm{mL}$ for both assays (Figure 1). The analytical detection threshold, defined as the lowest concentration of a serial detection assay where at least half of the PCR tubes are positive, was 10-fold lower for the Elitech assay compared to the Bio-Evolution one (0.1 parasite/mL versus 1 parasite/mL, respectively). When testing QCMD samples, all qualitative results were concordant (26 positive, 2 negative) for both qPCR assays except for 2 discrepant results (Table S1). The discrepant results were about TGDNA20C1-01 and TGDNA20C1-05 samples when extracted with SP200 cartridges: the first was positive and the second was negative with Bio-Evolution assay, and vice versa with Elitech. These two samples are expected positive at $6 \pm 4$ Toxoplasma/mL by the manufacturer. They were finally found positive when re-tested (in 2/3 reactions wells with the Elitech assay for the first sample, and in $1 / 3$ reactions wells with the Bio-Evolution assay for the second). Mean $\mathrm{Ct}$ values were systematically higher with Elitech than with Bio-Evolution (mean delta $\mathrm{Ct}=2.2 \pm$ $1.1 ; p$-value $<0.001)$.

Diagnostic performances in a clinical cohort. Among the 31 specimens included in the retrospective clinical cohort and tested in duplicate, qualitative results were concordant for 30 specimens (97\%): 18 positive results (both PCR wells of all duplicates were positive) and 12 negative results (Table S1). The only discordant result concerned a whole blood specimen, which was positive with Bio-Evolution in one reaction tube out of two $(\mathrm{Ct}=35.89)$, but negative for the duplicate with Elitech.

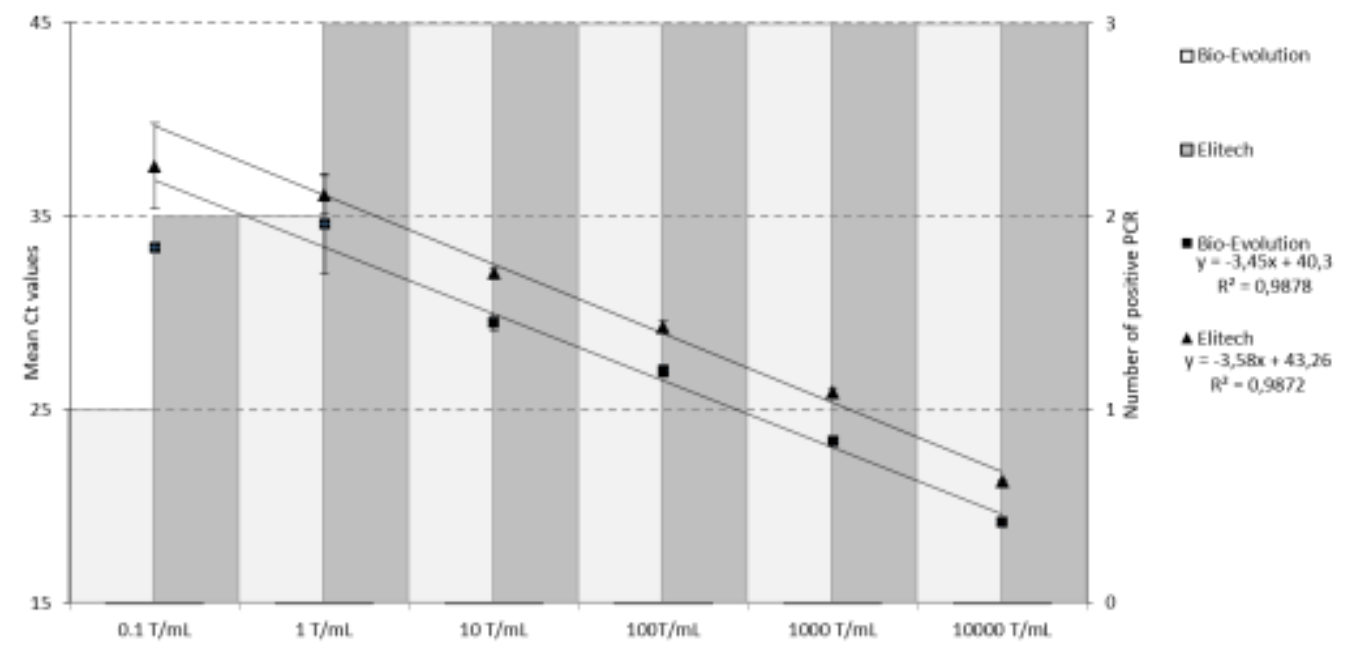

Figure 1. Serial dilution assays. Ten-fold serial dilution assays of a freeze-dried calibrated suspension $\left(10^{4}\right.$ Toxoplasma $/ \mathrm{mL}, T$. gondii type II) were performed in triplicate with Bio-Evolution (black square) and Elitech (black triangle) PCR assays. Histograms represent the number of positive PCR wells with Bio-Evolution (light grey) and Elitech (dark grey) (ranging from 1/3 to 3/3). Calibration curves were drawn based on positive samples with all triplicate wells positive and $\mathrm{SD}<0.5$; they allowed determining slopes and $\mathrm{R}^{2}$.

This specimen is a low positive sample. It had been found positive (in one reaction tube out of three) by the laboratory of the
Molecular Biology "Pole" (University Hospital of Montpellier) of the French NRC-T on their own extract analysed with 
their "in-house" qPCR using the PCR method published by Reischl et al. (11). This positivity was also supported by the clinical context, as this was a blood specimen collected seven days before a disseminated toxoplasmosis case. This discrepant specimen was finally also found positive with the Elitech assay (in 2/3 reaction wells). In addition, all DNA extracts were found to be free of PCR inhibitors using the internal control (IC) of both assays. Considering QCMD and clinical samples, mean $\mathrm{Ct}$ values for IC were $28.97 \pm 0.60$ and $31.41 \pm 0.94$ for Bio-Evolution and Elitech assays, respectively. Considering the whole clinical cohort, as observed with spiked samples, mean $\mathrm{Ct}$ values were systematically higher for the Elitech assay (mean delta $\mathrm{Ct}=1.8 \pm 0.7 ; p$-value < $0.001)$.

Good agreement of both PCR assays. The $\mathrm{Ct}$ values obtained using both methods were compared for each of the 54 concordant positive samples and plotted in a Bland-Altman graph (Figure 2A). There was a very good agreement between both methods, with only four samples out of the range of $\pm 1.96 \mathrm{SD}$. When $\mathrm{Ct}$ of BioEvolution were plotted against those obtained by Elitech (Figure 2B), correlation was high with $\mathrm{R}^{2}=0,949$.

In addition, the DNA extraction step was also tested on the four amniotic fluids of the cohort and on nine QCMD samples. They were extracted with each of the two DNA extraction cartridges (ELITe InGenius $^{\text {TM }}$ SP200 and ELITe InGenius ${ }^{\text {TM }}$ SP1000). Whatever the PCR assay, mean $\mathrm{Ct}$ values were decreased systematically with SP1000 cartridges, at least $0.22 \mathrm{Ct}$ to $5.93 \mathrm{Ct}$, and for 2 samples a positive result was obtained only when extraction was performed with SP1000 cartridges (Table 3).

\section{Discussion}

Design and rationale of the study. Diagnosis of congenital and disseminated toxoplasmosis mainly relies on molecular diagnosis. The repeated DNA element rep529 (GenBank accession number AF146527) $(11,12)$ was shown to provide high sensitivity to qPCR assays $(9,11)$ and has become the main DNA target used in most PCR methods, whether laboratorydeveloped or commercial (1). In this study, both assays target the rep529 region. The study was conducted to determine if the performances of the Bio-Evolution and Elitech PCR assays are maintained on the easy-to-use sample-to-result ELITe InGenius $^{\mathrm{TM}}$ PCR platform. Indeed, the Bio-Evolution PCR assay is not validated on this apparatus by the manufacturer and the previous evaluation of the Elitech PCR assay was performed using manual extraction methods and other thermocyclers (3). The possibility to combine extraction and amplification steps on the same apparatus ensures technical time saving for the lab staff with a reduced hands-on time (13) (this platform has a turnaround time of approximately 2.5 hours, from setup to result) and limits human errors. Yet, it is relevant to check the correct match between the DNA extraction and the PCR method (1). Many clinical specimens (peripheral blood, cord blood, placentas and amniotic fluids) and artificial spiked amniotic fluid samples of external quality controls from QCMD were tested in the study. Cerebrospinal fluid and broncho-alveolar lavage samples were not included. The retrospective nature of the design of the study may induce some limitations as clinical samples included have been frozen since their sampling. Yet it has been previously published that freezing and storage at $-20{ }^{\circ} \mathrm{C}$ provides adequate preservation of Toxoplasma gondii DNA for retrospective molecular 
A

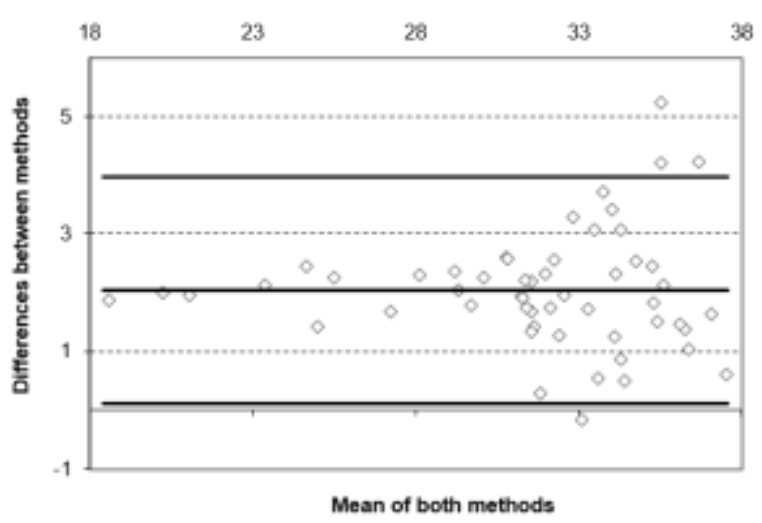

B

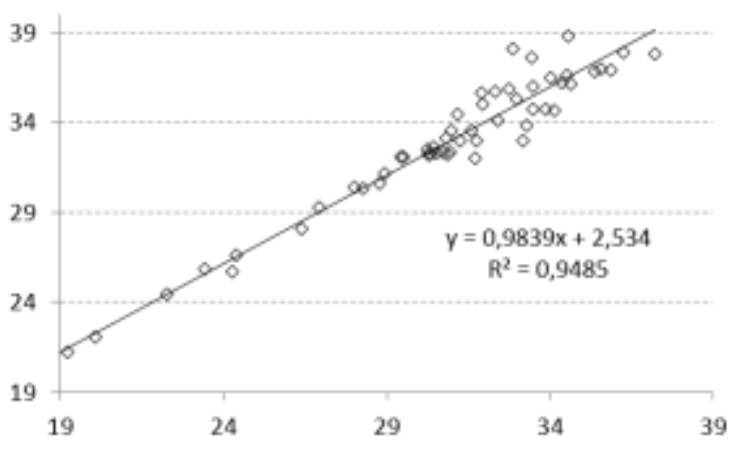

Figure 2. Bland-Altman and correlation plots representing the concordance between both Bio-Evolution and Elitech PCR assays performed on the Elitech platform. A. BlandAltman plot. For each positive samples by both methods (losange), Ct values were plotted, with the mean of both methods in abscissa and the difference between both methods in ordinate. The thick lines represent the means and the \pm 1.96 standard deviations. B. Correlation plot. Ct values obtained by Bio-Evolution PCR assay were plotted against those obtained by Elitech. Linear regression with its equation and R2 values is presented.

Mean Ct value

\begin{tabular}{ccccccc} 
Samples & \multicolumn{3}{c}{ Bio-Evolution assay } & \multicolumn{3}{c}{ Elitech assay } \\
& SP200 & SP1000 & $\Delta \mathbf{C t}^{\dagger}$ & SP200 & SP1000 & $\Delta \mathbf{C t}^{\dagger}$ \\
\hline AF*1 $^{\dagger}$ & 26.40 & 24.27 & $\mathbf{2 . 1 3}$ & 28.08 & 25.69 & $\mathbf{2 . 3 9}$ \\
AF*2 $^{*}$ & 34.02 & 32.40 & $\mathbf{1 . 6 2}$ & 36.48 & 34.13 & $\mathbf{2 . 3 5}$ \\
AF*3 $^{*}$ & 20.09 & 17.65 & $\mathbf{2 . 4 4}$ & 22.05 & 19.52 & $\mathbf{2 . 5 3}$ \\
AF*4 & 33.85 & 30.52 & $\mathbf{3 . 3 3}$ & 34.71 & 32.27 & $\mathbf{2 . 4 4}$ \\
TGDNA20C1-01 & $34.76^{\$}$ & 31.69 & $\mathbf{3 . 0 7}$ & Neg & 31.97 & $/$ \\
TGDNA20C1-01 & 34.54 & 31.94 & $\mathbf{2 . 6 0}$ & 38.77 & 35.02 & $\mathbf{3 . 7 5}$ \\
TGDNA20C1-01 & 31.89 & 31.26 & $\mathbf{0 . 6 4}$ & 35.61 & 33.00 & $\mathbf{2 . 6 2}$ \\
TGDNA20C1-04 & 34.38 & 33.47 & $\mathbf{0 . 9 1}$ & 36.20 & 34.72 & $\mathbf{1 . 4 8}$ \\
TGDNA20C1-04 & 35.57 & 30.24 & $\mathbf{5 . 3 3}$ & 36.94 & 32.46 & $\mathbf{4 . 4 9}$ \\
TGDNA20C1-04 & $34.51^{\$}$ & 32.75 & $\mathbf{1 . 7 6}$ & 36.64 & 35.82 & $\mathbf{0 . 8 2}$ \\
TGDNA20C1-05 & Neg & 32.31 & $/$ & 35.94 & 35.73 & $\mathbf{0 . 2 2}$ \\
TGDNA20C1-05 & $33.30^{\$}$ & 31.74 & $\mathbf{1 . 5 7}$ & 33.85 & 33.01 & $\mathbf{0 . 8 4}$ \\
TGDNA20C1-05 & $32.88^{\$}$ & 30.87 & $\mathbf{2 . 0 1}$ & $38.12^{\$}$ & 32.20 & $\mathbf{5 . 9 3}$ \\
\hline
\end{tabular}

Table 3. Comparison of two DNA extraction cartridges: SP200 and SP1000.

*AF: amniotic fluid. ${ }^{\dagger} \Delta \mathrm{Ct}$ : difference between $\mathrm{Ct}_{\mathrm{SP} 200}$ and $\mathrm{Ct}_{\mathrm{SP} 1000} .{ }^{\$}$ Only one positive in the duplicate. Neg: negative result at the first run.

analysis (14). Another potential bias of this study concerns the potential competing effect of the IC in case of low parasitic concentrations. Such effect was not tested in this study although it was previously described with this IC after manual extraction with EXTRAblood (ELITechGroup) (3). However, as the 
expected effect of this IC is deleterious in terms of performance, this does not call into question the conclusions of this study. The amplifications were performed in duplicate, except for the standards which were tested in triplicate. Indeed, it has been shown that the parasitic loads in congenital toxoplasmosis are often very low, with a median concentration in amniotic fluid estimated around 10 tachyzoites per $\mathrm{ml}$ (15), and low parasitic loads are also encountered during disseminated toxoplasmosis (16). Hence, (i) the PCR assays used for this diagnosis must be highly sensitive; and (ii) the French NRC$\mathrm{T}$ recommends the analysis of clinical samples in duplicate or triplicate to be able to detect these low parasitic loads (1).

A secondary aim of the study was to test the ELITe InGenius ${ }^{\text {TM }}$ SP1000 cartridge on amniotic fluids (allowing the extraction of $1 \mathrm{~mL}$ of template), as it is not validated on this matrix contrary to the SP200 cartridge (allowing the extraction of $0.2 \mathrm{~mL}$ of template).

DNA extraction step. A main difference between Bio-Evolution and Elitech PCR assays is the absence of an IC for the extraction step in the first one. Controlling DNA extraction is important as a failed extraction may lead to false negative results and cannot be detected in the absence of a specific control. In order to verify this step with Bio-Evolution, a second PCR targeting a commercial or a "laboratory-made" DNA extraction control is required. The Elitech PCR assay uses a stabilized solution containing two plasmid DNAs and the genomic RNA of MS2 phage as IC which checks extraction and amplification steps. When choosing a commercial PCR assay, the presence of an IC should be taken into account, especially in a context of quality management. It is necessary to remain critical concerning the IC chosen by the manufacturer. Indeed, as demonstrated by a recent study, the use of heterologous targets may not be considered as the best choice (17).
Concerning DNA extraction performed with SP1000 cartridge, interestingly, Ct values for $T$. gondii target were significantly decreased as compared to those obtained with the SP200 cartridge. This result is relevant as DNA is theoretically five-time more concentrated with the SP1000 cartridge comparatively with the SP200. For the QCMD samples extracted with the two cartridges, whereas all were positive when extracted with the SP1000 cartridges, several were inconstantly positive or negative when extracted with the SP200 cartridges. Despite the low number of samples tested, the particular interest of this reagent for the amniotic fluid samples is confirmed due to the often low parasitic load. A larger study based on amniotic fluids not artificially spiked with $T$. gondii should be performed to confirm these preliminary results. Centrifugation of large volume of amniotic fluid samples or all pauci cellular samples followed by elimination of the supernatant and testing either $200 \mu \mathrm{L}$ or $1000 \mu \mathrm{L}$ could also be tested. Furthermore, it might be interesting to assess the performances of the SP1000 cartridges on whole blood, which has not been validated by the manufacturer for this matrix.

DNA amplification step. Among the 31 clinical specimens tested, one whole blood sample was found inconsistently positive between both PCR assays. The Elitech assay finally found a positive result for this discrepant specimen after re-testing in triplicate (2 out of 3 positives). Among all the QCMD specimens, each PCR assay obtained one false negative result after the first PCR sets, and the results were finally concordant after re-testing in triplicate (1 or 2 out of 3 positives). These cases illustrate the interest of increasing the number of reactions when getting close to the sensitivity threshold of the methods. It would be interesting that PCR assay manufacturers include this recommendation in their manuals despite the potential extra cost induced. 
The specificity was excellent for both assays, without any false-positive result. However, contrary to the Elitech assay, the Bio-Evolution assay does not include the use of UDG, which is recommended to prevent carry-over contamination (1).

In total, PCR assays for the molecular diagnosis of toxoplasmosis commercialised by Bio-Evolution and Elitech presented good performances when used with the ELITe InGenius ${ }^{\mathrm{TM}}$ PCR platform, in accordance with the published performances with other PCR platforms (2,3). Interestingly, during the evaluation of the Elitech PCR assay performed by Robert-Gangneux et al., a similar calibrated Toxoplasma suspension prepared also by the Molecular Biology "Pole" of the French NRC-T was tested. Compared to those in this study, the results were poorer for the lowest concentrations, i.e. 1 and 0.1 parasite $/ \mathrm{mL}$, resulting in lower PCR performance scores (3). Although it is not possible to affirm that the calibration of the initial suspension and the serial dilutions were perfectly comparable between both studies, these discrepancies may highlight the impact of the extraction methods and the PCR platform on PCR performances, particularly for the lowest parasitic loads.

\section{Conclusion}

Overall, both PCR assays produced very good and comparable performances on the automated and integrated ELITe InGenius ${ }^{\mathrm{TM}}$ PCR platform. They are rapid, accurate, and easy-to-use methods for detection of $T$. gondii in clinical specimens with low parasitic loads, from whole blood to amniotic fluid. The DNA extraction cartridges proposed by the manufacturer of the PCR platform have a real interest for these key samples. The study reminds also the need for replicates.

\section{Acknowledgments}

The authors thank the Molecular Biology Pole of the French National Reference Center of Toxoplasmosis which provided all the specimens tested in this study.

This study was in part funded by 'Santé Publique France' through financial support of the Molecular Biology Pole of the French National Reference Center for Toxoplasmosis.

C. Nourrisson is the guarantor of this work and, as such, had full access to all of the data in the study and takes responsibility for the integrity of the data and the accuracy of the data analysis.

\section{Author contributor roles:}

$\mathrm{CN}$ : formal analysis, investigation, visualization, writing-original draft; $\mathrm{MM}$ : investigation; PP: resources, writing - review and editing; YS: conceptualization, methodology, supervision, writing review and editing.

\section{Conflict of interest}

The authors declare no conflict of interest.

\section{References}

1. Roux G, Varlet-Marie E, Bastien P, Sterkers Y, French National Reference Center for Toxoplasmosis Network. Evolution of Toxoplasma-PCR methods and practices: a French national survey and proposal for technical guidelines. Int J Parasitol 2018;48(9-10):701-7.

2. Filisetti D, Sterkers Y, Brenier-Pinchart M-P, Cassaing S, Dalle F, Delhaes L, Pelloux H, Touafek F, Varlet-Marie E, Yera H, Candolfi E, Bastien P.
Multicentric comparative assessment of the bio-evolution Toxoplasma gondii detection kit with eight laboratorydeveloped PCR assays for molecular diagnosis of congenital toxoplasmosis. J Clin Microbiol 2015;53(1):29-34.

3. Robert-Gangneux F, Brenier-Pinchart M-P, Yera H, Belaz S, Varlet-Marie E, Bastien P, Molecular Biology Study Group of the French National Reference 
Center for Toxoplasmosis. Evaluation of Toxoplasma ELITe MGB Real-Time PCR Assay for Diagnosis of Toxoplasmosis. J Clin Microbiol 2017;55(5):1369-76.

4. Yera H, Ménégaut L, Brenier-Pinchart M-P, Touafek F, Bastien P, Dalle F, Molecular Biology Study Group of the French National Reference Center for Toxoplasmosis. Evaluation of five automated and one manual method for Toxoplasma and human DNA extraction from artificially spiked amniotic fluid. Clin Microbiol Infect 2018;24(10):1100.e7-1100.e11.

5. Varlet-Marie E, Sterkers Y, Brenier-Pinchart M-P, Cassaing S, Dalle F, Delhaes L, Filisetti D, Pelloux $\mathrm{H}$, Touafek T, Yera H, Bastien P. Characterization and multicentric validation of a common standard for Toxoplasma gondii detection using nucleic acid amplification assays. J Clin Microbiol 2014;52(11):3952-9.

6. Lebech M, Joynson DH, Seitz HM, Thulliez P, Gilbert RE, Dutton GN, Ovlisen B, Petersen E. Classification system and case definitions of Toxoplasma gondii infection in immunocompetent pregnant women and their congenitally infected offspring. European Research Network on Congenital Toxoplasmosis. Eur J Clin Microbiol Infect Dis 1996;15(10):799-805.

7. Tissot Dupont D, Fricker-Hidalgo H, BrenierPinchart MP, Bost-Bru C, Ambroise-Thomas P, Pelloux H. Usefulness of Western blot in serological follow-up of newborns suspected of congenital toxoplasmosis. Eur $\mathbf{J}$ Clin Microbiol Infect Dis 2003;22(2):122-5.

8. Martino R, Maertens J, Bretagne S, Rovira M, Deconinck E, Ullmann AJ, Held T, Cordonnier C. Toxoplasmosis after hematopoietic stem cell transplantation. Clin Infect Dis 2000;31(5):1188-95.

9. Sterkers $\mathrm{Y}$, Varlet-Marie E, Cassaing $\mathrm{S}$, Brenier-Pinchart M-P, Brun S, Dalle F, Delhaes L, Filisetti D, Pelloux H, Yera H, Bastien P. Multicentric comparative analytical performance study for molecular detection of low amounts of Toxoplasma gondii from simulated specimens. J Clin Microbiol 2010;48(9):3216-22.
10. Bland JM, Altman DG. Statistical methods for assessing agreement between two methods of clinical measurement. Lancet Lond Engl 1986;1(8476):307-10.

11. Reischl U, Bretagne S, Krüger D, Ernault P, Costa J-M. Comparison of two DNA targets for the diagnosis of Toxoplasmosis by real-time PCR using fluorescence resonance energy transfer hybridization probes. BMC Infect Dis 2003;3:7.

12. Homan WL, Vercammen M, De Braekeleer J, Verschueren H. Identification of a 200- to 300-fold repetitive 529 bp DNA fragment in Toxoplasma gondii, and its use for diagnostic and quantitative PCR. Int $\mathbf{J}$ Parasitol 2000;30(1):69-75.

13. Totten AH, Leal SM, Ratliff AE, Xiao L, Crabb DM, Waites KB. Evaluation of the ELITe InGenius PCR Platform for Detection of Mycoplasma pneumoniae. J Clin Microbiol 2019;57(6)

14. Delhaes L, Filisetti D, Brenier-Pinchart M-P, Pelloux H, Yéra H, Dalle F, Sterkers Y, Varlet-Marie E, Touafek F, Cassaing S, Bastien P. Freezing and storage at $-20{ }^{\circ} \mathrm{C}$ provides adequate preservation of Toxoplasma gondii DNA for retrospective molecular analysis. Diagn Microbiol Infect Dis 2014;80(3):197-9.

15. Costa JM, Ernault P, Gautier E, Bretagne S. Prenatal diagnosis of congenital toxoplasmosis by duplex real-time PCR using fluorescence resonance energy transfer hybridization probes. Prenat Diagn $2001 ; 21(2): 85-8$

16. Daval S, Poirier P, Armenaud J, Cambon M, Livrelli V. Development of a real-time PCR assay for quantitative diagnosis of Toxoplasma gondii after allogeneic bone marrow transplantation. Pathol Biol (Paris) 2010;58(1):104-9.

17. Roux G, Ravel C, Varlet-Marie E, Jendrowiak R, Bastien P, Sterkers Y. Inhibition of polymerase chain reaction: Pathogen-specific controls are better than human gene amplification. PloS One 2019;14(9):e0219276.

\section{Supplementary Table S1. Raw data. (Available online only)}

For clinical samples, final diagnosis of congenital toxoplasmosis is adapted on case definitions according to Lebech et al. (6), with the only adjustment that molecular biology diagnosis is assimilated to cultivation approach. For disseminated samples in immunocompromised patients, clinical classification was either 'toxoplasma disease' or 'toxoplasma infection' according to to the European Group for Blood and Marrow Transplantation Infectious Diseases Working Party classification (8).

Pos: positive; Neg: negative; Inc. Pos: inconstantly positive; AF: amniotic fluid; NN: neonatal; EQA: external quality assessment; SDA: serial dilution assay; *: related sampe 